Article

\title{
Analyses of the Effect of Cycle Inlet Temperature on the Precooler and Plant Efficiency of the Simple and Intercooled Helium Gas Turbine Cycles for Generation IV Nuclear Power Plants
}

\author{
Arnold Gad-Briggs *, Theoklis Nikolaidis and Pericles Pilidis \\ Gas Turbine Engineering Group, Cranfield University, Cranfield MK43 OAL, UK; \\ t.nikolaidis@cranfield.ac.uk (T.N.); p.pilidis@cranfield.ac.uk (P.P.) \\ * Correspondence: a.a.gadbriggs@cranfield.ac.uk; Tel.: +44-797-353-9110 \\ Academic Editor: Antonio Ficarella \\ Received: 22 January 2017; Accepted: 20 March 2017; Published: 24 March 2017
}

\begin{abstract}
Nuclear Power Plant (NPP) precooler coolant temperature is critical to performance because it impacts the work required to increase the coolant pressure. Variation of the coolant temperature results in varied precooler hot gas temperatures, which are cooled before re-entry. For recirculation, the heat sink (usually sea water), could exit the precooler at unfavourable temperatures and impact the re-entering coolant, if not recirculated properly at the source. The study objective is to analyse the effects of coolant inlet temperature on the heat sink and cycle efficiency. The cycles are Simple Cycle Recuperated (SCR), Intercooler Cycle Recuperated (ICR), and Intercooled Cycle without Recuperation (IC). Results show that the co-current precooler provides favourable outlet heat sink temperatures but compromises compactness. For a similar technology level, the counter-current precooler yields excessive heat sink outlet temperatures due to a compact, robust, and efficient heat transfer design, but could be detrimental to precooler integrity due to corrosion, including the cycle performance, if not recirculated back into the sea effectively. For the counter-current, the ICR has the best heat sink average temperature ratio of 1.4; the SCR has 2.7 and IC has 3.3. The analyses aid the development of Gas Cooled Fast Reactors (GFRs) and Very High Temperature Reactors (VHTRs), where helium is used as the coolant.
\end{abstract}

Keywords: Gen-IV; efficiency; NPP; cycle; precooler; performance; simple; intercooled; recuperated

\section{Introduction}

Generation IV (Gen-IV) reactors intend on significantly changing Nuclear Power Plant (NPP) design [1], but as a non-greenhouse emitting source, the benefits as a main power generation alternative will not be explored if the design is complex. Complicated designs, which are derived from complex configurations, may boost capacity but at the expense of sound economics, if the plant efficiency does not provide justification for the costs [1]. In addition to simplifying the design, it is important to understand the factors that influence changes in plant cycle efficiency. The objective of this study is to analyse the cycle coolant inlet temperature after it exits from the precooler and to understand the effects on the heat sink and the cycle efficiency. A modeling and performance simulation tool created for this research work is used to carry out the task. The precooler designs of interest are the co-current and counter-current flows; the cycles of interest are the Simple Cycle Recuperated (SCR), Intercooled Cycle Recuperated (ICR), and the Intercooled Cycle without Recuperation (IC). The cycles are analysed in a closed Brayton direct configuration using helium as the working fluid. 


\subsection{Generation IV (Gen-IV) Systems}

The Gas-Cooled Fast Reactors (GFRs) and Very-High-Temperature Reactors (VHTRs) are the focus reactors of this study. The GFR is cooled with helium and has a high temperature threshold with a fast spectrum nuclear core. It has a Core Outlet Temperature (COT) of 850 to $950{ }^{\circ} \mathrm{C}$ with a closed efficient Brayton Cycle. Helium allows for single phase cooling in all instances and chemical compatibility due to its inertness and neutronic transparency. The VHTR also uses helium as a coolant in the gaseous phase and includes a reactor with a high temperature thermal capability (up to $1000{ }^{\circ} \mathrm{C}$ ). The reactor also utilises graphite moderation in the solid state due to the mechanical properties at high temperature. Furthermore, the chemical inertness of helium ensures no chemical reaction takes place with the graphite moderator. The planned and on-going development of demonstrators for the GFR and VHTR relate to the testing of basic concepts and performance phases, validation, and verification. These are discussed in [2].

\subsection{Applicable Cycles}

The three cycles pertaining to this study are extensively described in [3]. Figures $1-3$ show the cycle schematics for the SCR, ICR, and IC, respectively. All cycles include compressor(s) and a turbine as part of the turbomachinery, the precooler, and the reactor. However, the recuperator, which is used to provide heat exchange from the turbine outlet hot gas to the High Pressure (HP) coolant, only features in the SCR and ICR. The IC has a Low Pressure (LP) region, which is maintained by the Low Pressure Compressor (LPC) prior to the coolant entering an intercooler. The intercooler reduces the coolant temperature to the same as the cycle inlet temperature $\left(T_{1}\right)$ before it enters the High Pressure Compressor (HPC), whereby temperature increase is achieved at the exit of the HPC. The ICR also employs an intercooler and a second compressor albeit at a modest Overall Pressure Ratio (OPR), which is split between both compressors. The modest pressure ratio is due to the heat exchange provided by the recuperator. This is not the case with the SCR as it only utilises a single compressor and no intercooler but has the benefit of raising the reactor Core Inlet Temperature (CIT) due to the recuperator, meaning the cycle only requires a low Pressure Ratio (PR). The other notable difference are the cycle efficiencies. The ICR and IC increase the Specific Work (SW) and Useful Work (UW) by reducing the work required by the compressors. This means that the ICR has an efficiency which is $\sim 3 \%$ greater than the SCR and $6.6 \%$ greater than the IC when optimised turbine cooling methods are considered [3]. However, the ICR has a disadvantage in that the increased capacity, due to the number of components, adds complexity to the plant configuration. On the other hand, the IC offers a simpler component configuration than the ICR but it requires reactor Core Outlet Temperatures $\geq 1000{ }^{\circ} \mathrm{C}$ to significantly improve the efficiency, which will make it competitive. This was investigated as part of this research work and is documented in [3]. The benefits of using helium as opposed to air are documented in [4-6] and provide a good theoretical platform for off-design operation, control, and transient operation of a helium nuclear gas turbine plant.

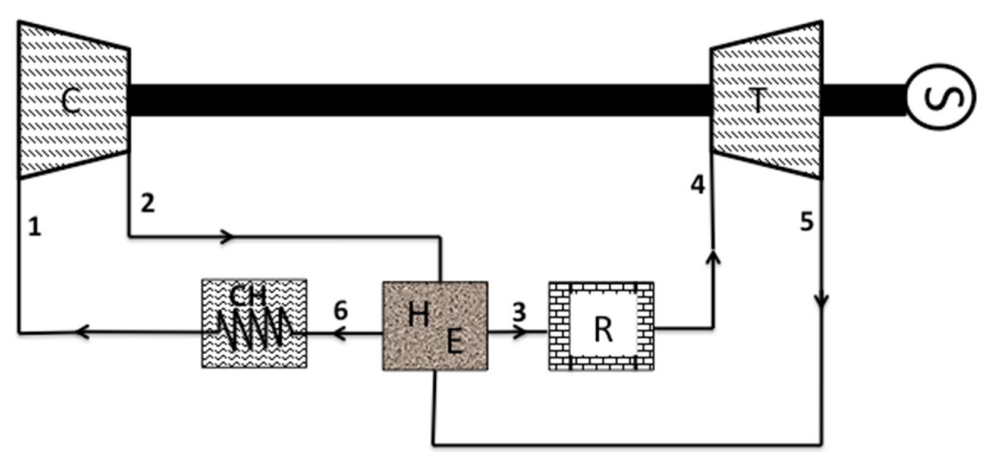

Figure 1. Typical Simple Cycle Recuperated (SCR) [7]. Single shaft spool connection to the turbomachinery which includes a precooler, reactor, and recuperator. The schematic shows 6 stations. 


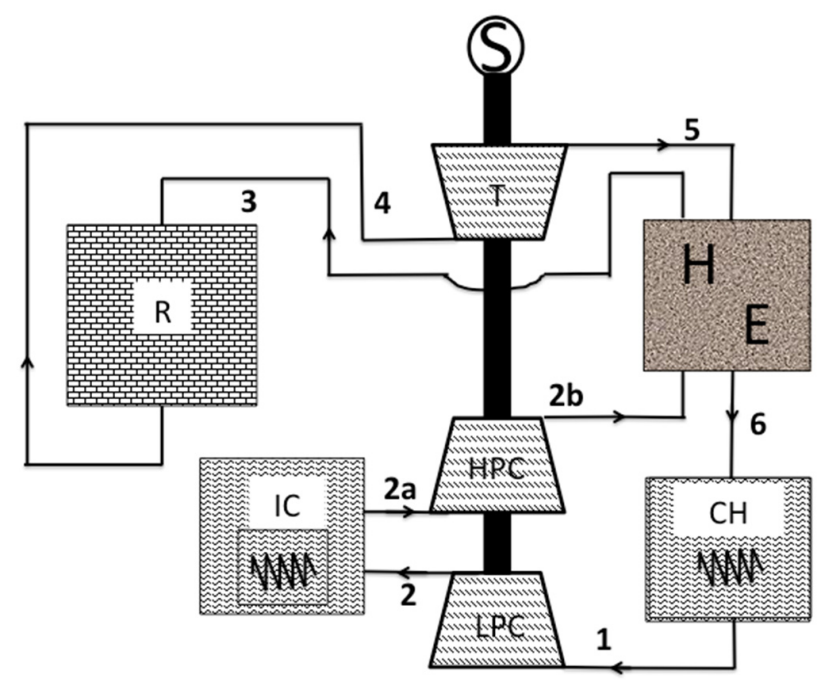

Figure 2. Typical Intercooled Cycle Recuperated (ICR) [8]. Single shaft spool connection to the turbomachinery, which includes an Low Pressure Compressor (LPC), High Pressure Compressor (HPC), and turbine as part of the turbomachinery, precooler, intercooler, reactor, and recuperator. The schematic shows 8 stations (station 2 comprising 3 stations).

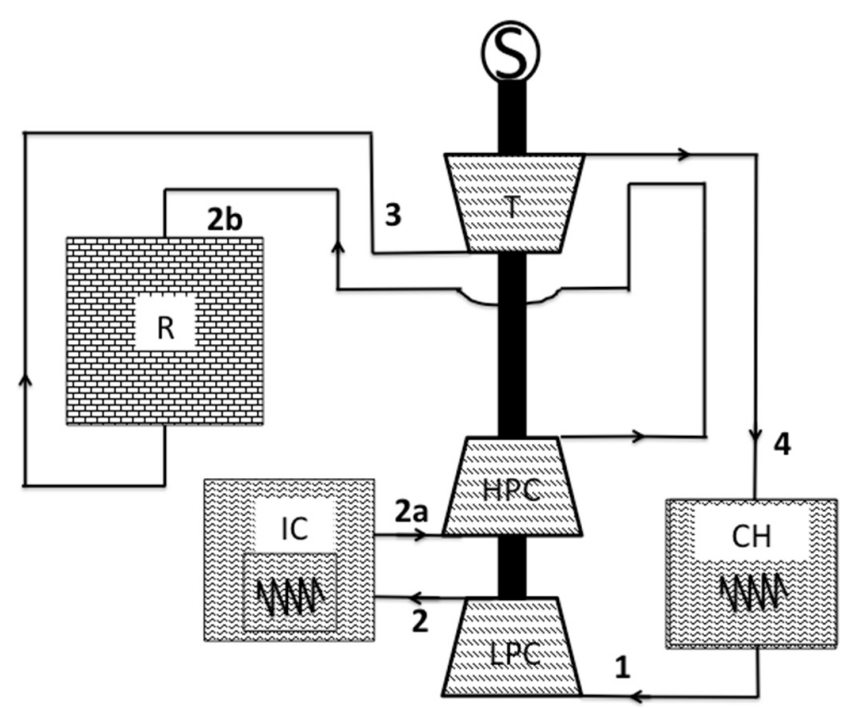

Figure 3. Typical Intercooled Cycle (IC) [9]. Single shaft spool connection to the turbomachinery, which includes an LPC, HPC, and turbine as part of the turbomachinery, precooler, intercooler, and reactor, but no recuperator. The schematic shows 6 stations (station 2 comprising 3 stations).

\subsection{Precooler Design Method}

The precooler as a heat exchanger ensures that the coolant is cooled by the heat sink at the compressor inlet to achieve the required cycle inlet temperature. The heat sink in this case is seawater, which flows through the precooler and is recirculated back at the source. The design considerations, flow velocity, and sizing calculations for typical arrangements are extensively documented in $[10,11]$. For this study, the focus is on the design methods, which determine the heat transfer rate of the precooler using the inlet and outlet conditions. There are two design methods considered in this study. For the precooler, the Logarithmic Mean Temperature Difference (LMTD) method is considered, whilst the Number of Transfer Units (NTU) method is adopted for the recuperator. The LMTD method for the precooler takes into account two flow arrangements; the co-current (or parallel flow) and counter-current flow configuration, which are illustrated in Figure $4 a, b$. The counter-current flow is 
robust and compact in size due to the high rate of heat exchange made possible by the opposite flow of the helium to the heat sink. On the other hand, the co-current flow does not offer the high rate of heat exchange due to the flows being parallel to each other, consequentially resulting in a larger precooler, in comparison to the counter-current design for a similar technology.

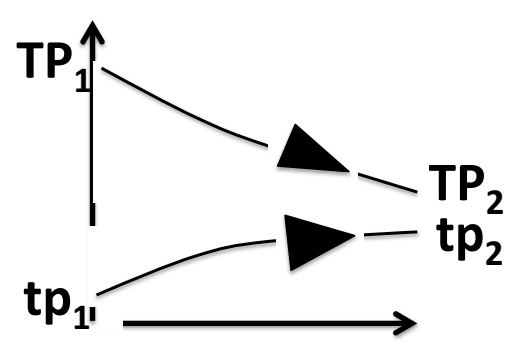

(a)

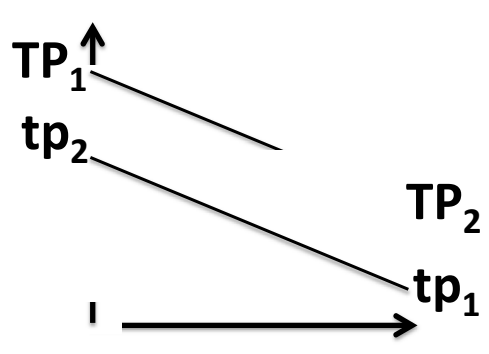

(b)

Figure 4. Logarithmic Mean Temperature Difference (LMTD) Co-Current (a) and Counter-Current (b) Flows for the Precooler. $\mathrm{TP}_{1}$ and $\mathrm{tp}_{1}$ represent the inlet temperatures of the coolant and heat sink (seawater), respectively. $\mathrm{TP}_{2}$ and $\mathrm{tp}_{2}$ represent the outlet temperatures of the coolant and heat sink, respectively. (a) shows that the flows are parallel to each other, indicating a bigger precooler but with a modest exit temperature of the heat sink $\left(\mathrm{tp}_{2}\right) ;(\mathbf{b})$ shows that the flows are in opposite directions and ensures better heat exchange, therefore the size of the counter-current precooler is significantly reduced but with potentially higher exit heat sink temperature $\left(\mathrm{tp}_{2}\right)$.

\section{Materials and Methods-Modelling and Simulation of Nuclear Power Plants (NPPs)}

Table 1 provides the key Design Point (DP) data required for modeling of the NPPs. The modeling and simulation was performed using a FORTRAN tool, which was designed specifically for this research work (see Figure 5 for the structure). With consideration of the DP performance, the tool calculates the station properties based on known cycle inlet conditions and the reactor Core Outlet Temperature (COT) in order to derive the NPP power output and cycle efficiency. The effects on cycle output, efficiency, and capacity can also be analysed when changes to the aforementioned parameters are investigated. It is also capable of Off Design Point (ODP) performance calculations using component maps in order to derive the optimum points whereby all components are at equilibrium to ensure the maximum efficiency possible during part power operation. Furthermore, transient part power control and load following capabilities can also be simulated using inventory pressure control. The tool also incorporates the optimum cooling calculation in order to determine percentage of mass flow rate required for turbine cooling based on the blade metal temperature, which improves the cycle efficiency. However, the aspects of the model that are utilised in this study relate to DP modelling and calculation, cooling, and analysis.

The proceeding sub-sections describe the equations that are embedded within the code environment for steady-state DP calculations. The material is taken directly from $[1,3,9]$ which were written by the authors and is part of the overall research work, which this study is linked to. 
Table 1. Design Point Input Values for Modelling.

\begin{tabular}{|c|c|c|c|c|}
\hline Design Point Performance & SCR & ICR & IC & Units \\
\hline Inlet Temp. $\left(T_{1}\right)$ & 28 & 28 & 28 & ${ }^{\circ} \mathrm{C}$ \\
\hline TET (Core Outlet Temp.) $\left(T_{4}\right)$ & 950.0 & 950.0 & 950.0 & ${ }^{\circ} \mathrm{C}$ \\
\hline Core Inlet Temp. $\left(T_{3}\right)$ & 678 & 599 & 448 & ${ }^{\circ} \mathrm{C}$ \\
\hline Inlet Pressure $\left(P_{1}\right)$ & 3.21 & 3.21 & 3.21 & $\mathrm{MPa}$ \\
\hline OPR & 2 & 2.6 & 13 & - \\
\hline Mass Flow Rate at Inlet $\left(m_{1}\right)$ & 410.4 & 410.4 & 410.4 & $\mathrm{~kg} / \mathrm{s}$ \\
\hline * Compressor Efficiency (Isentropic) & 90 & 90 & 90 & $\%$ \\
\hline * Turbine Efficiency (Isentropic) & 94.5 & 94.5 & 94.5 & $\%$ \\
\hline * Precooler LMTD & 38 & 38 & 38 & - \\
\hline * Pecuperator Effectiveness & 96 & 96 & - & $\%$ \\
\hline Pressure Loss (Precooler) & 2.5 & 2.5 & 2.5 & $\%$ \\
\hline Pressure Loss (Intercooler ICR only) & - & 2.5 & 2.5 & $\%$ \\
\hline Pressure Loss (Reactor) & 2 & 2 & 2 & $\%$ \\
\hline Pressure Loss (Recup. HP side) & \multirow{2}{*}{$\begin{array}{c}6 \\
\text { combined }\end{array}$} & \multirow{2}{*}{$\begin{array}{c}6 \\
\text { combined }\end{array}$} & - & \multirow[t]{2}{*}{$\%$} \\
\hline Pressure Loss (Recup. LP side) & & & - & \\
\hline $\begin{array}{c}\text { Reactor Cooling Flow (\% of Mass } \\
\text { Flow Rate) }\end{array}$ & 0.25 & 0.25 & 0.25 & $\%$ \\
\hline Compressor Work & 227 & 299 & 1063 & MW \\
\hline Turbine Work & 512.8 & 686.8 & 1537 & MW \\
\hline Heat Input & 575.6 & 743.7 & 1040 & MW \\
\hline Specific Work (NPP Capacity) & 0.7 & 0.95 & 1.16 & $\mathrm{MW} / \mathrm{kg} / \mathrm{s}$ \\
\hline Useful Work & 285.7 & 387.9 & 474.4 & MW \\
\hline Plant Efficiency & 49.6 & 52.2 & 45.6 & $\%$ \\
\hline
\end{tabular}

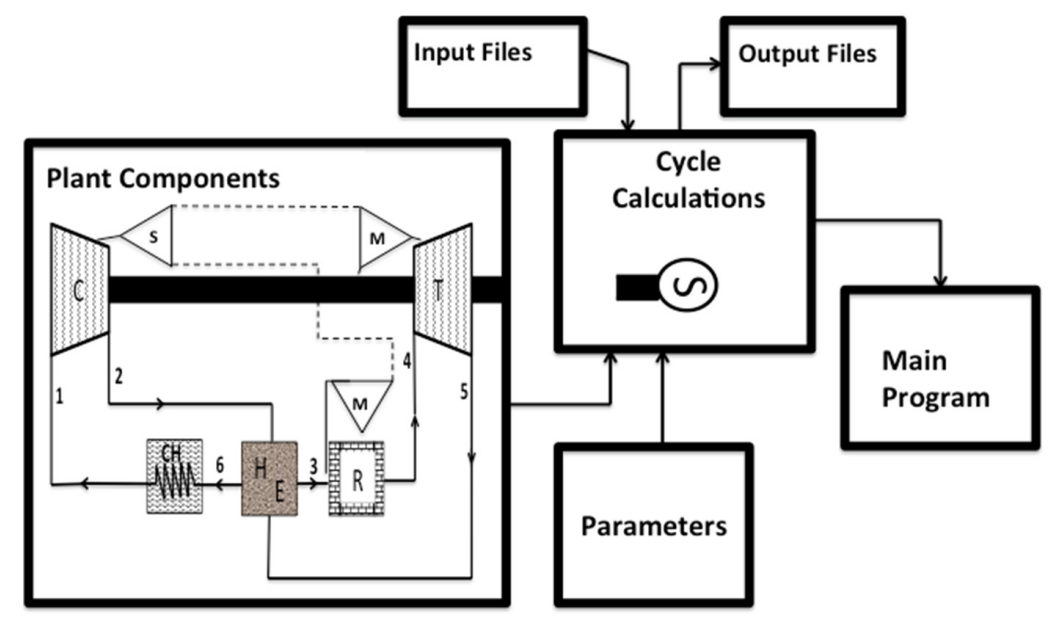

Figure 5. Modelling Structure [3]. The structure shows a typical SCR single shaft configuration with all the components and helium circuit including the bleed off point from the compressor (S denotes splitter), which channels cool the reactor, and the turbine via M (denoted as mixer). Parameters and input files for the calculations are also defined to station conditions and cycle output. The structure is interchangeable with ICR and IC. 


\subsection{Compressor}

Prerequisite parameters for performance design considerations of the compressor include the compressor pressure ratio, compressor inlet conditions (temperature, pressure, and mass flow rate), component efficiency, and the working fluid gas properties $(C p$ and $\gamma)$. The compressor outlet pressure (in Pa) is:

$$
P_{\mathcal{c}_{\text {out }}}=P_{c_{\text {in }}} \cdot P R_{c}
$$

The isentropic efficiency of the compressor is $\frac{T_{\text {rise }} e_{\text {ideal }}}{T_{\text {rise }} e_{\text {actual }}}$ and is also indicative of the specific work input or total temperature increase. Thus, the temperature $\left({ }^{\circ} \mathrm{K}\right)$ at the exit can be derived from the inlet temperature, pressure ratio, isentropic efficiency, and ratio of specific heats:

$$
T_{\mathcal{c}_{\text {out }}}=T_{c_{\text {in }}} \cdot\left[1+\frac{\left(\frac{P_{c_{\text {out }}}}{P_{c_{\text {in }}}}\right)^{\frac{\gamma-1}{\gamma}}-1}{\eta_{i_{s_{c}}}}\right]
$$

The mass flow rate $(\mathrm{kg} / \mathrm{s})$ at the inlet is equal to the mass flow rate at the outlet as there are no compositional changes:

$$
m_{\mathcal{c}_{\text {out }}}=m_{c_{\text {in }}}
$$

The compressor work $(W)$ is the product of the mass flow rate, specific heat at constant pressure, and the temperature delta:

$$
C W=m_{c} \cdot C p_{h e} \cdot\left(\Delta T_{c}\right)
$$

whereby

$$
\Delta T_{c}=T_{\mathcal{c}_{\text {out }}}-T_{c_{\text {in }}}
$$

Bypass splitters (S in Figure 5) are incorporated within the performance simulation tool to allow for compressed coolant to be bled for reactor and turbine cooling.

\subsection{Turbine}

Prerequisite parameters of the turbine include the turbine inlet conditions (temperature, pressure, and mass flow rate), the pressure at the outlet, component efficiency, and the working fluid gas properties $(\mathrm{C} p$ and $\gamma)$. The temperature $\left({ }^{\circ} \mathrm{K}\right)$ at the outlet is derived from the following expression:

$$
T_{t_{\text {out }}}=T_{t_{\text {in }}} \cdot\left\{1-\eta_{i_{s_{t}}}\left[1-\left(\frac{P_{t_{\text {out }}}}{P_{t_{\text {in }}}}\right)^{\frac{\gamma-1}{\gamma}}\right]\right\}
$$

As with the compressor, Equations (3) and (4) also apply to the turbine for the mass flow rate $(\mathrm{kg} / \mathrm{s})$ conditions and turbine work $(W)$, but:

$$
\Delta T_{t}=T_{t_{\text {in }}}-T_{t_{\text {out }}}
$$

A mixer ( $\mathrm{M}$ in Figure 5) is incorporated within the performance simulation tool to allow for the coolant to mix with the hot gas to simulate turbine cooling.

\subsection{Recuperator (SCR and ICR Only)}

The calculation method for the rate of heat transfer is based on the Number of Transfer Units (NTU) method, which has been documented by [13] and applied for complex cross flow heat exchangers by [14]. The algorithm in the code ensures satisfactory results and numerical stability. Prerequisite parameters include the recuperator effectiveness, hot and cold inlet conditions (pressure 
and temperature), and the delta pressures due to the losses at the high and low pressure sides. Effectiveness of the recuperator is given as:

$$
\varepsilon_{r e}=\frac{q_{r_{r e a l}}}{q_{r e_{\max }}}
$$

The maximum amount of heat flux $\left(\mathrm{W} / \mathrm{m}^{2}\right)$ of the recuperator, $q_{r_{e_{\max }}}$ must consider the hot and cold inlet conditions. It must also consider the minimum specific heat because it is the fluid with the lowest heat capacity that experiences the maximum change in temperature. This is expressed as:

$$
q_{r e_{\max }}=\frac{C p_{h_{\text {min }}} \cdot\left(T_{r e_{h o t}}^{\prime}-T_{r e_{c o l d}}^{\prime}\right)}{A}
$$

and the real heat flux $\left(\mathrm{W} / \mathrm{m}^{2}\right)$ is:

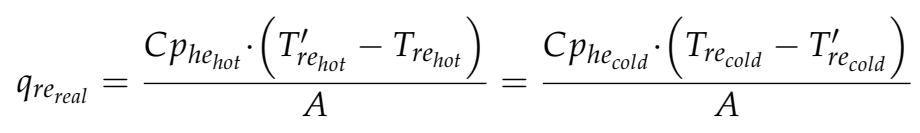

With helium as the working fluid, $C p$ is considered to be constant, and thus $C p_{h e_{\text {min }}}=C p_{h e_{\text {cold }}}=$ $C p_{h e_{h o t}}$ in the energy balance equation. The temperatures at the hot and cold ends can be obtained when considering Equation (10) (either hot or cold sides) and considering an arbitrary effectiveness. The temperature for the cold end $\left({ }^{\circ} \mathrm{C}\right)$ is then expressed as:

$$
T_{r e_{\text {cold }}}=T_{r e_{\text {cold }}}^{\prime}+\left[\varepsilon_{r e} \cdot\left(T_{r e_{\text {hot }}}^{\prime}-T_{r_{\text {cold }}}^{\prime}\right)\right]
$$

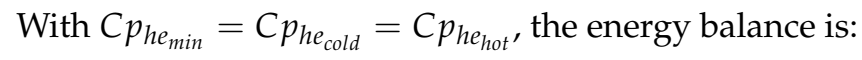

$$
\left[m_{r_{\text {cold }}} \cdot\left(T_{r_{\text {cold }}}-T_{r e_{\text {cold }}}^{\prime}\right)\right]=\left[m_{r e_{h o t}} \cdot\left(T_{r e_{h o t}}^{\prime}-T_{r e_{h o t}}\right)\right]
$$

Thus, the hot outlet $\left({ }^{\circ} \mathrm{C}\right)$ is:

$$
T_{r e_{h o t}}=T_{r e_{h o t}}^{\prime}-\left[\frac{m_{r e_{c o l d}} \cdot\left(T_{r e_{\text {cold }}}-T_{r e_{\text {cold }}}^{\prime}\right)}{m_{r e_{\text {hot }}}}\right]
$$

With regards to the pressures, the exit conditions can be calculated if the pressure drops (\%) across the hot and cold sides are known:

$$
\begin{gathered}
P_{r e_{\text {cold }}}=P_{r e_{\text {cold }}}^{\prime} \cdot\left(1-\Delta P_{r e_{\text {HPloss }}}\right) \\
P_{r e_{\text {hot }}}=P_{r e_{\text {hot }}}^{\prime} \cdot\left(1-\Delta P_{r e_{L P l o s s}}\right)
\end{gathered}
$$

Due to no compositional changes, the mass flow rate $(\mathrm{kg} / \mathrm{s})$ conditions are:

$$
\begin{gathered}
m_{r e_{h o t}}=m_{r e_{h o t}}^{\prime} \\
m_{r e_{\text {cold }}}=m_{r e_{\text {cold }}}^{\prime}
\end{gathered}
$$

\subsection{Precooler and Intercooler}

Prerequisite parameters for the precooler and intercooler (ICR and IC only) take into account that the components are upstream of the first and second compressors, respectively, thus the compressor 
inlet temperature and pressure are of importance, including the pressure losses. The conditions for the precooler are as follows:

$$
\begin{gathered}
T_{p c_{\text {out }}}=T_{c_{\text {in }}} \\
P_{p c_{\text {in }}}=P_{p c_{\text {out }}} \cdot\left(1+\Delta P_{p c_{\text {loss }}}\right) \\
m_{p c_{\text {out }}}=m_{p c_{\text {in }}}
\end{gathered}
$$

With regards to the intercooler, Equations (18)-(20) also apply, but are differentiated for the intercooler. An addition of a second compressor for ICR only, means that the pressure ratio for both compressors is determined as:

$$
P R_{i c}=\sqrt[i c]{P R}
$$

whereby the ic coefficient denotes the number of intercoolers in the cycle +1 , leading to a reduction in the pressure ratio per compressor (ICR only). The IC also has a second compressor, but a significantly higher OPR is required for the IC in the absence of a recuperator. Furthermore, an even split using Equation (21) does not provide the required pressure rise per compressor for the most optimum cycle efficiency. The OPR is determined by calculations that specifically look at the optimum split ratio between the LPC and the HPC that gives the best cycle efficiency.

\subsection{Modular Helium Reactor}

The helium reactor is a heat source with pressure losses. The prerequisites are the thermal heat input from burning the fuel and the known reactor design pressure losses. The heat source does not introduce any compositional changes, thus the mass flow rate $(\mathrm{kg} / \mathrm{s})$ is:

$$
m_{M H R_{\text {out }}}=m_{M H R_{\text {in }}}
$$

Pressure taking into account losses (\%):

$$
P_{M H R_{\text {out }}}=P_{M H R_{\text {in }}} \cdot\left(1-\Delta P_{M H R_{\text {loss }}}\right)
$$

and the thermal heat input (Wth) is:

$$
Q_{M H R}=m_{M H R_{i n}} \cdot C p_{h e} \cdot\left(\Delta T_{M H R}\right)
$$

whereby

$$
\Delta T_{M H R}=T_{M H R_{\text {out }}}-T_{M H R_{\text {in }}}
$$

A mixer (see Figure 5) is incorporated within the code to allow for coolant to be mixed with the heated fluid upstream of the reactor, to simulate Reactor Pressure Vessel (RPV) cooling.

\subsection{Cooling Calculations}

Prerequisites to calculate the cooling flow from the compressor exit, which is required for the cycle (cooling flow is taken as a percentage of mass flow rate) are the turbine metal temperature (simply known as blade metal temperature), compressor exit coolant temperature, TET (simply known as gas), and cooling effectiveness. The cooling effectiveness $(<1)$ is expressed as:

$$
\varepsilon_{\text {cool }}=\frac{\left(T_{\text {gas }}-T_{\text {blade }}\right)}{\left(T_{\text {gas }}-T_{\text {coolant }}\right)}
$$

The cooling effectiveness as a function of the cooling flow (percentage of mass flow rate) has been empirically derived by the National Aeronautics and Space Administration NASA for various cooling technologies [14-16]. With regards to the choice of technology, film impingement forced convection is considered the technology for immediate and near term deployment based on current turbine cooling 
developments in [17]. With consideration of the application, data from NASA studies were used to define the cooling effectiveness as a function of the cooling flow. The defined cooling conditions were verified against the analysis, which featured empirical data for film impingement forced convection as published in [17]. The calculated results were comparable to the empirical results. The calculated results were judged to be satisfactory for this study based on good comparability.

\subsection{Cycle Calculations}

The useful work, specific work, and thermal efficiency output values are of interest after executing each set of thermodynamic station parametric calculations. The useful work (UW), that is the work available for driving the load, is:

$$
U W=T W-C W
$$

whereby Equation (27) is also applicable to the ICR and IC cycles, but the $C W$ is the summation of the LPC and HPC work requirements to be delivered by the turbine. The specific work or capacity of the plant $(\mathrm{W} / \mathrm{kg} / \mathrm{s})$ is:

$$
S W=U W / m
$$

and the thermal efficiency (\%) of the cycle is:

$$
\eta_{t h}=U W / Q_{M H R}
$$

\subsection{Logarithmic Mean Temperature Difference (LMTD) for Precooler Design}

For a generic heat exchanger such as the precooler, the heat duty defines the amount of heat transferred by a known hot fluid quantity to a known cold fluid quantity for a given time. This is expressed as:

$$
q=h \cdot A_{p c} \cdot \Delta T_{\log \text { mean }}
$$

whereby $q$ is the heat duty and defines the thermal rating, $h$ is the overall heat transfer coefficient which is dependent on the material conductivity, geometry, flow properties, specific heat capacity and the individual convection heat transfer, and conductivity of the hot and cold fluids, $A_{p c}$ is the exchange area of the precooler, and $\Delta T_{\log _{\text {mean }}}$ is the Logarithmic Mean Temperature Difference (LMTD). The LMTD is interchanageble with the NTU method adopted for the recuperator and is the temperature driving force of the heat transfer process because it is the difference in the hot and cold fluid. More heat is transferred as a result of a favourable LMTD depending on the design of the precooler (co-current or counter current), if the assumption remains that there are constant flow rates and fluid thermal properties. For a precooler of co-current or counter-current flow, if the heat transfer is set to occur along a specific axis $(x)$ from point $\mathrm{A}$ to $\mathrm{B}$, for two fluids called 1 and 2 , with their temperature along $x$ known as $T_{1}(x)$ and $T_{2}(x)$, then the exchange at that localised point $(x)$ is proportional to the temperature delta:

$$
q(x)=\frac{h\left(T_{1}(x)-T_{2}(x)\right)}{D}=\frac{h(\Delta T(x))}{D}
$$

whereby $D$ is the distance between the two fluids. The heat that leaves the fluid causes a temperature gradient according to Fourier's law:

$$
\begin{gathered}
\frac{d T_{1}}{d x}=k_{a}\left(T_{1}(x)-T_{2}(x)\right)=-k_{a} \Delta T(x) \\
\frac{d T_{2}}{d x}=k_{b}\left(T_{2}(x)-T_{1}(x)\right)=k_{b} \Delta T(x)
\end{gathered}
$$

Thus, the summation of Equations (32) and (33) becomes:

$$
\frac{d \Delta T}{d x}=\frac{d\left(T_{2}-T_{1}\right)}{d x}=\frac{d T_{2}}{d x}-\frac{d T_{1}}{d x}=k \Delta T(x)
$$


and considers that $k=k_{a}+k_{b}$. The full exchange is derived by integrating the local heat transfer from point $A$ to $B$ :

$$
q=\int_{A}^{B} q(x) d x=\frac{h}{D} \int_{A}^{B} \Delta T(x) d x=\frac{h}{D} \int_{A}^{B} \Delta T d x
$$

with the exchange area $A_{p c}$ being point $A$ to $B$ (length) multiplied by the distance of the internal pipe $D$ :

$$
q=\frac{h A_{p c}}{(B-A)} \int_{A}^{B} \Delta T d x=\frac{h A_{p c} \int_{A}^{B} \Delta T d x}{\int_{A}^{B} d x}
$$

substituting $x$ for the temperature difference $\Delta T$ in Equation (36) gives:

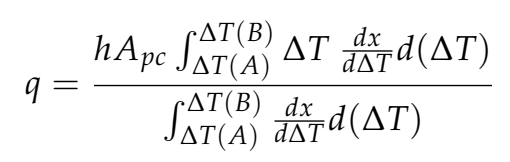

and substituting the relationship for delta $T$ (as derived in Equation (34)) in Equation (37) yields:

$$
q=\frac{h A_{p c} \int_{\Delta T(A)}^{\Delta T(B)} \frac{1}{k} d(\Delta T)}{\int_{\Delta T(A)}^{\Delta T(B)} \frac{1}{k \Delta T} d(\Delta T)}
$$

thus from integration and in relation to Equation (30), $q$ is expressed as:

$$
q=h \cdot A_{p c} \cdot \Delta T_{\log _{\text {mean }}}=h \cdot A_{p c} \cdot \frac{\Delta T(B)-\Delta T(A)}{\ln \frac{\Delta T(B)}{\Delta T(A)}}
$$

Using the portion of Equation (39) relating to $\Delta T_{\log _{\text {mean }}}$ and with reference to Figure 4, the co-current and counter-current flow configurations are defined as follows:

$$
\begin{gathered}
\text { Co }- \text { Current }=\Delta T_{\log _{\text {mean }}}=\frac{\Delta T(B)-\Delta T(A)}{\ln \frac{\Delta T(B)}{\Delta T(A)}}=\frac{\left(T P_{1}-t p_{1}\right)-\left(T P_{2}-t p_{2}\right)}{\ln \frac{\left(T P_{1}-t p_{1}\right)}{\left(T P_{2}-t p_{2}\right)}} \\
\text { Counter }- \text { Current }=\Delta T_{\log _{\text {mean }}}=\frac{\Delta T(B)-\Delta T(A)}{\ln \frac{\Delta T(B)}{\Delta T(A)}}=\frac{\left(T P_{1}-t p_{2}\right)-\left(T P_{2}-t p_{1}\right)}{\ln \frac{\left(T P_{1}-t p_{2}\right)}{\left(T P_{2}-t p_{1}\right)}}
\end{gathered}
$$

The tool was used to match the DP conditions of known NPPs in the literature in order to verify its functionality. The matched results were considered satisfactory for the purpose of this study. The precooler design equations assume that both the co-current and counter-current flows for the specific precooler are of the same technology design as per the LMTD in Table 1.

\section{Results}

This section summarises for each cycle inlet temperature between 25 and $55^{\circ} \mathrm{C}$, the results from the analysis of the hot gas temperatures at the precooler inlet, the heat sink outlet temperatures, and comparison of the cycle performances for each precooler design.

\subsection{Hot Gas Temperatures at Precooler Inlet}

This subsection details the results of the station calculations to determine the temperature of the hot gas helium going into the precooler. With reference to Figures 1-3, the stations of concern are station 6 (SCR and ICR) and station 4 (IC). With reference to Figure 4 and Equations (40) and (41), the hot gas helium at the inlet into the precooler is known as $\mathrm{TP}_{1}$. The results are plotted in Figure 6 and are shown as ratios of the hot gas to the cycle/compressor inlet temperature $\left(T_{1}\right)$, as a function of the cycle/compressor inlet temperature $\left(T_{1}\right)$. 


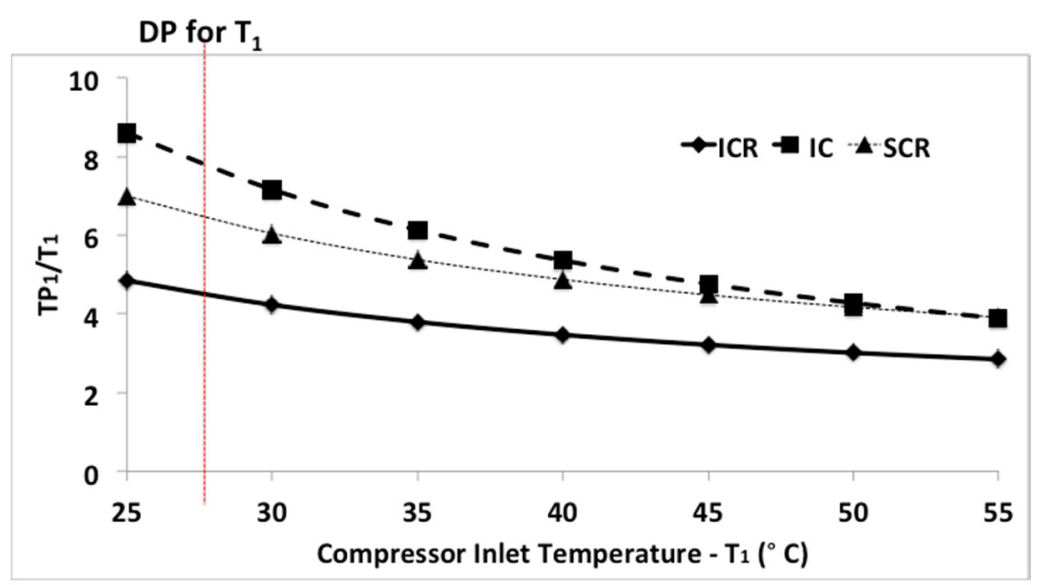

Figure 6. Hot Gas Helium at Precooler Inlet. Hot gas helium is normalised by the respective cycle/compressor inlet temperatures.

The results show that the IC has the highest hot gas temperature at the inlet to the precooler up to a compressor inlet temperature of $50{ }^{\circ} \mathrm{C}$. At $55^{\circ} \mathrm{C}$, the SCR has the highest temperature. The ICR has the lowest hot gas temperatures. The nature of the SCR and ICR curves indicate that the hot gas temperatures increase as the inlet conditions are increased, albeit not at a linear rate. This is not the case for the IC as the curve suggests a constant hot gas. The effects of the hot gas on the heat sink temperature at the precooler outlet are shown in the proceeding subsections.

\subsection{Heat Sink Outlet Temperatures}

The cycle heat sink outlet temperatures post heat exchanges are plotted in Figures 7-9 for the co-current and counter-current designs. With reference to Figure 4 and Equations (40) and (41), the heat sink precooler outlet temperature is known as tp $\mathrm{t}_{2}$ and is shown as ratios of the hot gas to the cycle/compressor inlet temperature $\left(T_{1}\right)$, as a function of the cycle/compressor inlet temperature $\left(T_{1}\right)$.

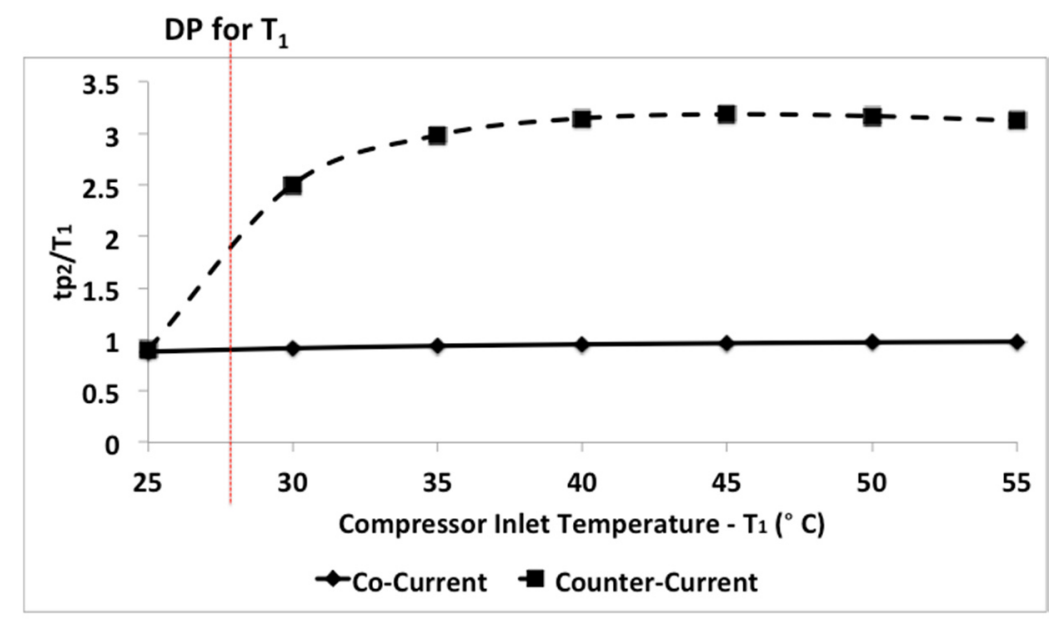

Figure 7. Heat Sink Outlet Temperature for SCR. The heat sink outlet temperature is normalised by the respective cycle/compressor inlet temperatures. 


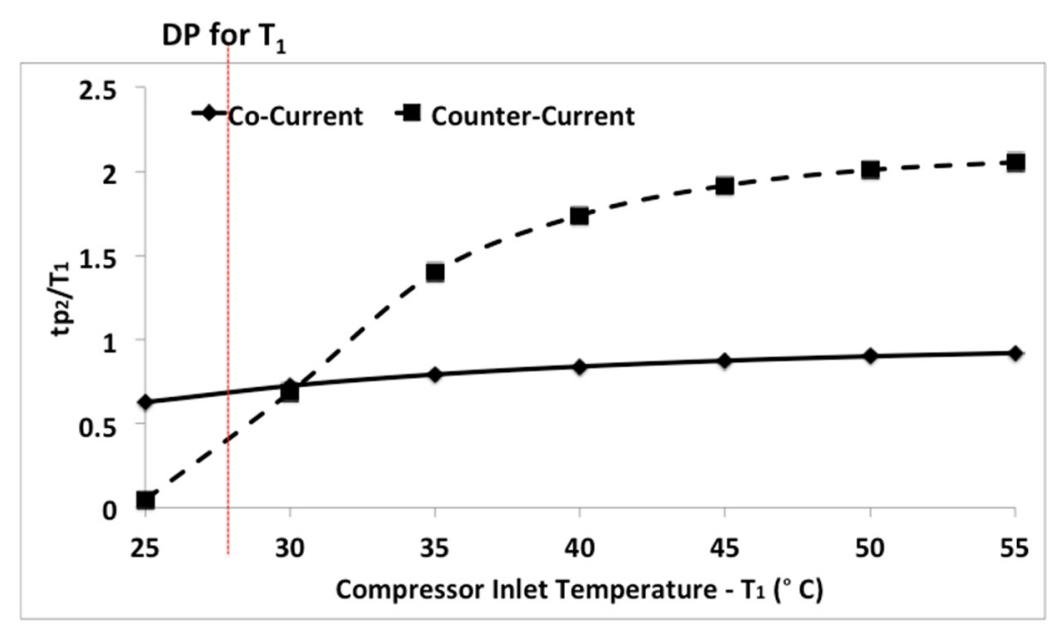

Figure 8. Heat Sink Outlet Temperature for ICR. The heat sink outlet temperature is normalised by the respective cycle/compressor inlet temperatures.

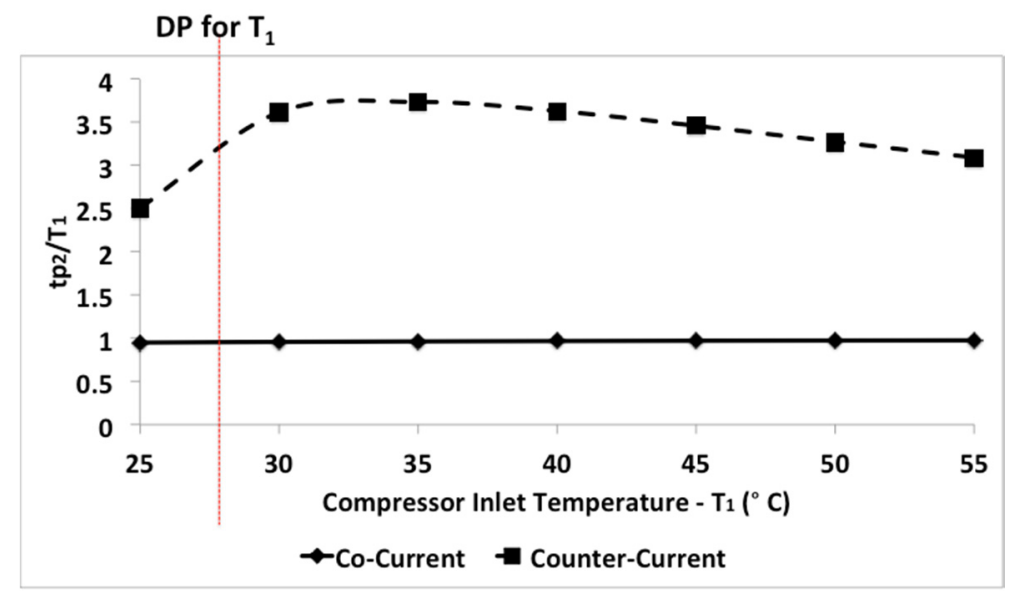

Figure 9. Heat Sink Outlet Temperature for IC. The heat sink outlet temperature is normalised by the respective cycle/compressor inlet temperatures.

The results show that the IC has the biggest difference between the counter-current and the co-current designs up to $50^{\circ} \mathrm{C}$; at $55^{\circ} \mathrm{C}$, the SCR has the biggest difference (see Figure 7) due to the IC showing a downward trend in Figure 9. The ICR shows the smallest difference between both precooler designs but more importantly, the outlet temperatures for both designs are the lowest amongst the three cycles.

\subsection{Comparison of Cycles' Precooler Performance (Heat Sink Outlet Temperature)}

The performance of the co-current and counter current precooler designs are plotted in Figures 10 and 11, respectively, for the various cycles. With reference to Figure 4 and Equations (40) and (41), the heat sink precooler outlet temperature is known as $\mathrm{tp}_{2}$ and is shown as ratios of the hot gas to the cycle/compressor inlet temperature $\left(T_{1}\right)$, as a function of the cycle/compressor inlet temperature $\left(T_{1}\right)$. 


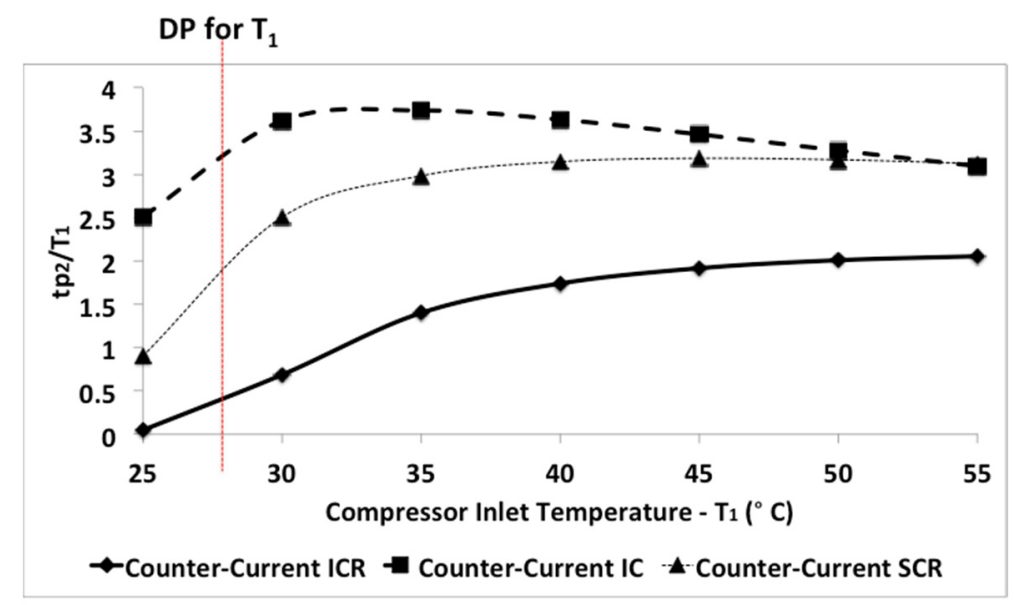

Figure 10. Comparison of Heat Sink Outlet Temperature for the Counter-Current Precooler. The heat sink outlet temperature is normalised by the respective cycle/compressor inlet temperatures.

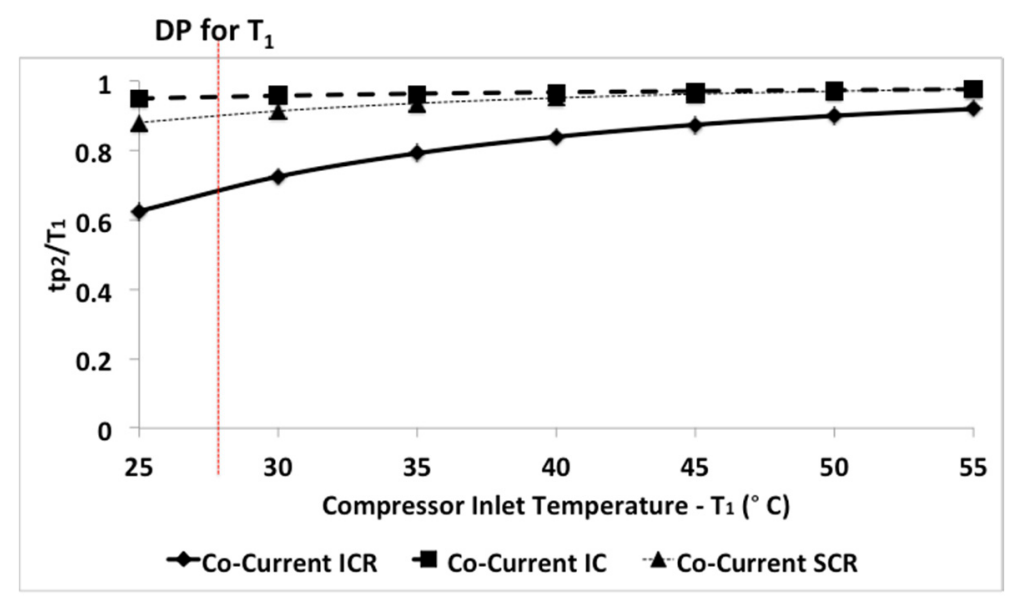

Figure 11. Comparison of Heat Sink Outlet Temperature for the Co-Current Precooler. The heat sink outlet temperature is normalised by the respective cycle/compressor inlet temperatures.

The IC has the highest heat sink temperature for the cycle inlet temperatures up to $50{ }^{\circ} \mathrm{C}$. For the counter-current flow precooler design (Figure 10), the IC has an average temperature ratio of 3.3, while the SCR has a temperature ratio of 2.7 and the ICR has the lowest ratio at 1.4. For the co-current flow precooler design (Figure 11), the same trend as noted for the counter-current flow was observed, but the temperature ratios are much lower, with negligible differences between the cycles. The IC has an average temperature ratio of 0.97 ; the SCR has an average of 0.94 , whilst the ICR has an average of 0.81 .

\section{Discussion}

It is clear that the hot gas helium temperature at the inlet to the precooler has a significant effect on the heat sink exit temperatures. The results show that the IC has the highest heat sink temperatures at the exit and this direct significance is evident in the average figures of hot gas at the inlet of each cycle. The IC has the highest average of $214.4^{\circ} \mathrm{C}$ for the hot gas; the SCR is $195^{\circ} \mathrm{C}$ and the ICR is $138.7^{\circ} \mathrm{C}$. With reference to Figure 6, the IC curve for the temperature ratio indicates a constant hot gas precooler inlet temperature due to the decreasing nature. The reason for this notable difference in comparison to the SCR and ICR is due to the recuperator effect. The temperatures at the inlet to the hot gas LP section of the recuperator have similar trends to the observations noted for the IC, suggesting that the heat exchange that takes place in the recuperator reduces with increasing precooler outlet/cycle 
inlet temperature $\left(T_{1}\right)$. Furthermore, the intercooler in the ICR ensures that the temperature of the compressed coolant is low, thereby utilising more of the hot gas temperature exchange. Thus the intercooler in the IC enables more of the generated power to be absorbed by the compressor and the turbine as more mass flow is compressed, but the SCR depends wholly on the recuperator when the compressor work is low. The benefit of this to the SCR (Figure 1) is the improved cycle efficiency of $4 \%$ in comparison to the IC (Figure 3), but the SCR has a more complex arrangement and plant size due to the recuperator, whereby the IC has a simpler arrangement. The ICR (Figure 2) has the most complex arrangement and is the largest of the plant cycles because of the recuperator and intercooler. The cycle efficiency benefit over the SCR is $\sim 3 \%$ at optimum turbine cooling conditions and $6.6 \%$ when compared to the IC (see Figure 12 for efficiency comparisons), but the increased efficiency is inversely proportional to the reduced hot gas temperature. The opposite of this statement holds true for the IC. For the SCR and ICR, the increases in hot gas at the precooler inlet due to the recuperator are primarily a result of the compressor/cycle inlet temperature $\left(T_{1}\right)$. For every $1{ }^{\circ} \mathrm{C}$ rise in compressor/cycle inlet temperature, the resulting increases in the hot gas are $1.8^{\circ} \mathrm{C}$ for the SCR and $0.92{ }^{\circ} \mathrm{C}$ for the ICR.

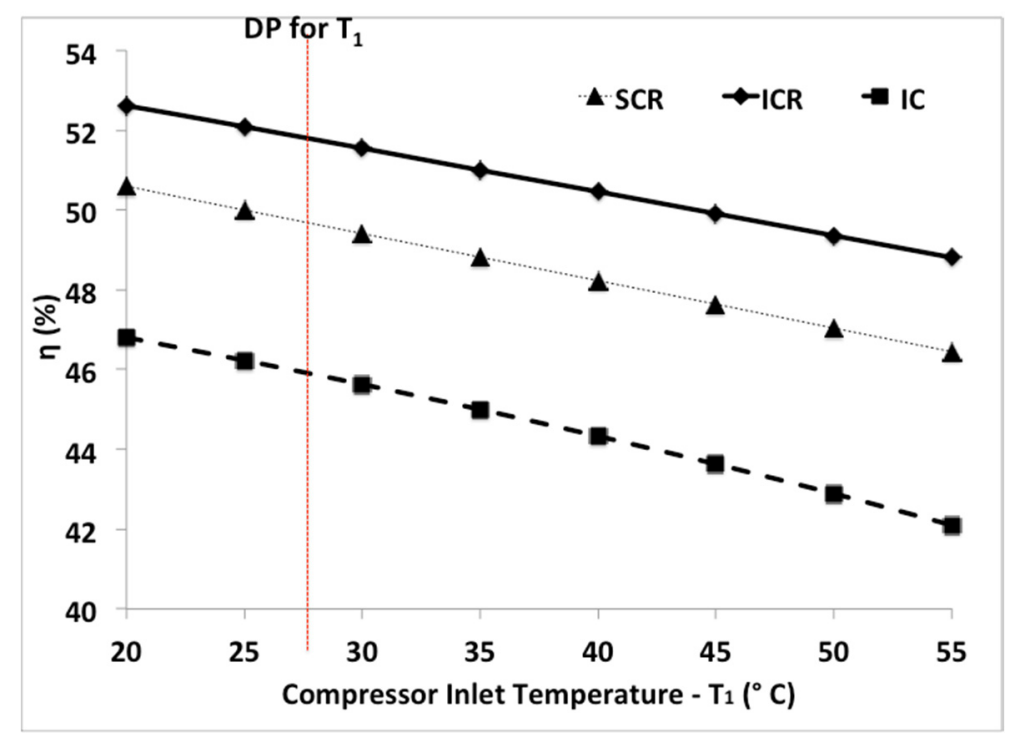

Figure 12. Effect of Cycle Inlet Temperature $\left(T_{1}\right)$ on Cycle Efficiencies. The trend shows decreasing efficiencies for all the cycles as the cycle inlet temperature increases.

When the focus turns to the effect of the hot gas on the heat sink outlet temperatures, the co-current precooler design shows that the average temperature increases are modest. For every degree rise in $T_{1}$, the ICR has the highest degree rise of $0.82{ }^{\circ} \mathrm{C}$ for the heat sink outlet temperature; the SCR has an average rise of $0.29^{\circ} \mathrm{C}$ per degree rise at $T_{1}$ and the IC has no rise in the heat sink outlet temperature. With regards to the counter-current design, the rise in heat sink outlet temperatures are pronounced at $T_{1}$ temperatures that are $<35^{\circ} \mathrm{C}$ and generally show a significant downward trend as $T_{1}$ exceeds $35^{\circ} \mathrm{C}$. When temperatures between 25 and $35{ }^{\circ} \mathrm{C}$ are considered, a $1{ }^{\circ} \mathrm{C}$ increase in $T_{1}$ results in a $7{ }^{\circ} \mathrm{C}$ increase for the SCR, a $5.5^{\circ} \mathrm{C}$ increase for the IC, and a $4.5^{\circ} \mathrm{C}$ increase for the ICR. When the full range of analysed temperatures are considered $\left(25\right.$ to $\left.55^{\circ} \mathrm{C}\right)$, the averages are $5^{\circ} \mathrm{C}$ for the $\mathrm{SCR}$, $3.7^{\circ} \mathrm{C}$ for the ICR, and $3.6^{\circ} \mathrm{C}$ for the IC. The reason for the SCR showing the greatest rise is due to the increased average of the hot gas, thus indicating that the variation in temperature is more pronounced for the SCR. The opposite of this statement holds true for the IC, as it has the least variation across the temperature range because of the comparable hot gas outlet temperatures across the cycle inlet temperature range. Nonetheless, the degree rises of the counter-current design are only critical when the baseline heat sink outlet temperatures at $25^{\circ} \mathrm{C}$ are considered. The IC has the highest baseline heat sink outlet temperature of $62.8^{\circ} \mathrm{C}$ at a $T_{1}$ of $25^{\circ} \mathrm{C}$ for the counter-current design; the SCR has $22.5^{\circ} \mathrm{C}$ 
and the ICR is below the International Standard Atmosphere (ISA) temperature. This is evident in the significant differences of the temperature ratios between 25 and $35^{\circ} \mathrm{C}$ in Figure 10 and is a stark contrast to the co-current design in Figure 11.

The concern here is that the co-current precooler design is ideal for all cycle inlet temperatures as the heat sink exit temperature is not significantly affected. However, for a moderate heat exchange rate per square meter, the benefit of a compact design is compromised because a larger heat exchanger is required. On the other hand, the compactness offered by the counter-current design due to the high exchange rate per square meter results in excess outlet temperature of the heat sink. At these temperatures, a phase change (vapourisation) of the seawater would be observed, prompting the need for a condensation and return medium. This phase change will also increase corrosiveness in the heat sink passages. Although seawater has a maximum temperature of typically $<40{ }^{\circ} \mathrm{C}$ in the hottest regions of the world, the expelled seawater could potentially increase the mean temperature of the incoming seawater, if the expelled water at the outlet is not recirculated effectively.

Due to environmental constraints, the inlet temperatures into the compressor may be difficult to control. The problem becomes exacerbated in hot climates, which will result in reduced cycle output and investment return when compared to a much cooler climate for the same level of capital investment and initial operating costs. Figure 12 shows the effects of the analysed temperature range on the cycle efficiencies of all three cycles.

With reference to Figure 12, the compressor inlet temperature affects the work demand of the compressors. This demand is quantified by the fact that for every $1{ }^{\circ} \mathrm{C}$ rise in the cycle inlet temperature, the effect is between a $0.3 \%$ to $0.5 \%$ increase in compressor work $(W)$ ) of the cycles, which affects the useful work $(W)$ available for the generator. The increase in $\mathrm{CW}$ correlates to the drop in cycle efficiencies of between $0.5 \%$ and $0.6 \%$ (direct delta percentage) per $5{ }^{\circ} \mathrm{C}$ increase. With consideration of this effect, it is important that the precooler design and recirculation of the heat sink is carefully implemented to avoid unfavourable cycle inlet temperatures, but more importantly for sound economics and to maximise the output against the operational costs. Furthermore, the choice of cycle based on the region in the world is very important. The IC has the lowest cycle efficiency but studies as part of this research work have demonstrated that the IC cycle efficiency can be significantly increased to make the cycle more competitive with SCR and ICR by increasing the COT of the reactor to temperatures in excess of $1000{ }^{\circ} \mathrm{C}$ [3]. With excessive temperatures at the precooler heat sink outlet, the co-current precooler design seems like the best choice for the IC, but to achieve a comparable level of technology to the counter-current design, the precooler has to be very large in size and the design has to be of a fin ribbed type arrangement with turbulators and intricate geometry, which will be challenging to manufacture, thus impacting the capital costs of the NPP. To understand the size implications, Figure 13 illustrates a simplified level of heat exchange for both designs for the same size and technology level. It is clear that for a 'close to' $100 \%$ heat exchange in a counter-current configuration, the co-current only produced close to $50 \%$ heat exchange for the same size [18].

The counter-current design is very efficient and transfers more heat per unit mass, but it may not be suited in extreme hot conditions without an efficient condensing and return medium. On this basis, it would be prudent to utilise the hot gas of the IC for use in an adjoining processing facility prior to returning to the precooler. The SCR would be suitable in cooler and mild climates, but not in a hot climate as it would be challenging to justify its potential size due to the recuperator, in addition to a large co-current precooler as the counter-current precooler would yield unfavourable heat sink return temperatures for cycle inlet temperatures above $30^{\circ} \mathrm{C}$. Furthermore, an adjoining processing plant may improve the operational business case but the size of the plant would need to be significantly up scaled, which would prove to be a disadvantage because of the increase in capital costs. The ICR offers the best performance figures in cold and hot climates in terms of minimising the potential for high inlet temperatures. This is due to the modest heat sink exit conditions with a counter-current precooler design, in addition to the best efficiency figures. However the size of the NPP due to the inclusion 
of a recuperator and an intercooler adds complexities to the construction and requires significant capital investment.

\section{Counter-Current}

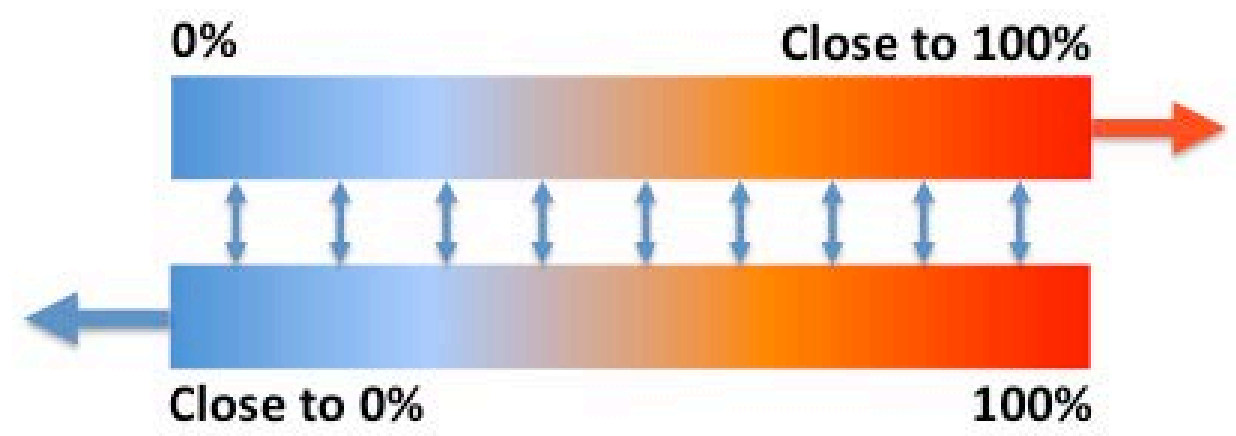

$100 \%$ Close to $50 \%$

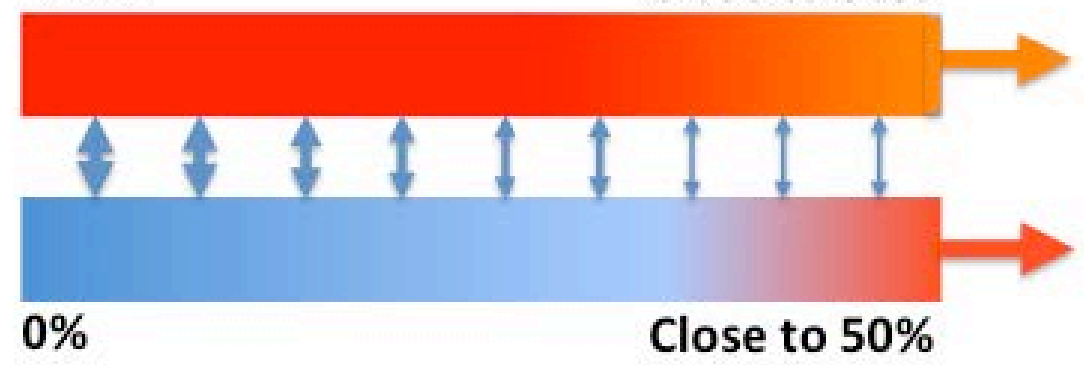

\section{Co-Current}

Figure 13. Size and Technology vs. Heat Exchange Comparison. Diagrams show that for the same size and technology level, the heat exchange is less than $50 \%$ for the co-current precooler.

\section{Conclusions}

In summary, the objective of this study was to analyse the cycle coolant inlet temperature after it exits from the precooler and to understand the effects on the seawater heat sink and the cycle thermal efficiency. The results provide a good basis to support preliminary design, testing, validation, and verification activities of Gas Cooled Fast Reactors (GFRs) and Very High Temperature Reactors (VHTRs) for Generation IV Nuclear Power Plants (NPPs). The main conclusions are:

- The Intercooled Cycle without recuperation (IC) has the highest hot gas temperature at the inlet to the precooler for a compressor inlet temperature $\leq 50{ }^{\circ} \mathrm{C}$. At a compressor inlet temperature $>50{ }^{\circ} \mathrm{C}$, the Simple Cycle Recuperated (SCR) has the highest hot gas temperature at the precooler inlet. This indicates that the type of precooler design is critical to both cycles in order to ensure that modest heat sink exit temperatures are achieved. Modest heat sink temperatures will have a favourable effect on the helium temperature at the compressor inlet. This is necessary to maintain the design point thermal efficiencies of both cycles. The Intercooled Cycle Recuperated (ICR) has the lowest hot gas temperature observed, hence the precooler basis within the ICR configuration is design compactness.

- The effect of the hot gas temperature at the inlet to the co-current precooler is negligible. The heat sink exit temperatures are modest. This indicates that recirculation for the purpose of cooling 
the helium will not lead to adverse temperatures at the inlet of the compressor, and thus no unfavourable effect on the cycle thermal efficiencies. With regards to the counter-current design, rises in the heat sink outlet temperatures are pronounced at cycle inlet temperatures that are $<35^{\circ} \mathrm{C}$, but generally show a significant downward trend as cycle inlet temperatures exceed $35^{\circ} \mathrm{C}$. This indicates that the recirculation effect using this precooler design in the temperature range of concern can result in unfavourable helium coolant temperatures at the compressor inlet, which will reduce the cycle thermal efficiency.

- When the baseline cycle inlet helium temperature of $25^{\circ} \mathrm{C}$ is considered, the IC has the highest heat sink outlet temperature for the counter-current design, the SCR has a temperature above the International Standard Atmosphere (ISA), and the ICR is below the ISA temperature. This is evident in the significant differences of the temperature ratios between 25 and $35^{\circ} \mathrm{C}$ and is a stark contrast to the co-current design. At high baseline temperatures, the heat sink outlet temperatures become very unfavourable and not ideal for maintaining cycle thermal efficiencies.

- The co-current precooler design is ideal for all cycle inlet temperatures as the heat sink exit temperature is not significantly affected. However, for a moderate heat exchange rate per square meter, the benefits of a compact design are compromised because a larger heat exchanger is required. This impacts the size of the plant and the maintenance costs.

- The compactness offered by the counter-current design due to the high exchange rate per square meter results in excess heat sink outlet temperatures. At these temperatures, a phase change (vapourisation) of the seawater will be observed, prompting the need for a condenser in the return medium, which will add to the cost of the precooler assembly. Hot sea water corrosion is also likely to occur at the heat sink passage, which will reduce the time between the maintenance and replacement of parts. Furthermore, the expelled seawater could potentially increase the mean temperature of the incoming seawater, if the expelled water at the outlet is not recirculated effectively.

- Drops in cycle efficiencies of between $0.5 \%$ and $0.6 \%$ (direct delta percentage) were observed when the cycle helium inlet temperatures were increased per $5{ }^{\circ} \mathrm{C}$. With consideration of this effect, it is important to understand the techno-economical impact to the cycle. The precooler design needs to consider the average ambient conditions and the cycle configuration. This is necessary prior to deciding on the design, in order to ensure that sound economics are achieved and to limit the costs of running the plant.

Acknowledgments: The authors wish to thank the Gas Turbine Engineering Group at Cranfield University (Cranfield, UK) for providing the necessary support in progressing this research study.

Author Contributions: Arnold Gad-Briggs and Pericles Pilidis conceived and designed the experiments; Arnold Gad-Briggs created the performance and simulation model, performed the experiments, reviewed and analysed the data; Theoklis Nikolaidis reviewed the code algorithm and output behind the performance and simulation model, and reviewed and analysed the data; Pericles Pilidis analysed the data; Arnold Gad-Briggs drafted the paper; Pericles Pilidis and Theoklis Nikolaidis reviewed the draft paper and added changes for final publication.

Conflicts of Interest: The authors declare no conflict of interest.

\section{Nomenclature}

\section{Notations}

A

$\mathrm{Cp}$

$\mathrm{CW}$

$D$

$h$

k

\author{
Area $\left(\mathrm{m}^{2}\right)$ \\ Spec. Heat of Gas at Constant Pressure $(\mathrm{J} / \mathrm{kg} \cdot \mathrm{K})$ \\ Compressor Work (W) \\ Distance (m) \\ Heat Transfer Coefficient \\ Thermal Conductivity $(\mathrm{W} / \mathrm{m} / \mathrm{K})$
}




\section{m}

$Q$

$q$

P

PR

SW

$T$

TW

W

UW

\section{Greek Symbols}

$\gamma$

$\Delta$

$\varepsilon$

$\eta$

Subscripts

blade

$c$

$c_{\text {in }}$

$c_{\text {out }}$

cool

coolant

e

gas

he

he $\min$

ic

$i s_{C}$

is $t$

MHR

$\mathrm{MHR}_{\text {in }}$

$\mathrm{MHR}_{\text {loss }}$

MHR out

$\log _{\text {mean }}$

$p c_{\text {in }}$

$p c_{\text {loss }}$

$p c_{\text {out }}$

re

re cold

re hot

re HPloss

re LPloss

re real

remax

th

$t$

$t_{\text {out }}$

$t_{\text {in }}$

Superscripts

,

Abbreviations

C

$\mathrm{CH}$

COT

DP
Mass Flow Rate (kg/s)

Reactor Thermal Heat Input

Heat Flux/Duty $\left(\mathrm{W} / \mathrm{m}^{2}\right)$

Pressure $(\mathrm{Pa})$

Pressure Ratio

Specific Work/Power Output (W/Kg/s)

Temperature $\left(\mathrm{K}\right.$ or $\left.{ }^{\circ} \mathrm{C}\right)$

Turbine Work (W)

Work (W)

Useful Work (W)

Ratio of Specific Heats

Delta, Difference

Effectiveness (Heat Exchanger; cooling)

Efficiency

Turbine Temperature (also known as Blade Temp.)

Compressor

Compressor Inlet

Compressor Outlet

Cooling

Compressor Exit Coolant

Power for Electrical Conversion

Turbine Entry Temperature

Helium

Helium with minimum gas conditions

Intercooled Cycle; intercooled coefficient

Isentropic (Compressor)

Isentropic (Turbine)

Reactor (Heat Source)

Reactor (Heat Source) Inlet

Reactor (Heat Source) Pressure Losses

Reactor (Heat Source) Outlet

Logarithmic Mean Temperature Difference

Precooler Inlet (also applicable to intercooler)

Precooler Pressure Losses (same as above)

Precooler Outlet (same as above)

Recuperator

Recuperator cold side

Recuperator hot side

Recuperator High Pressure Losses

Recuperator Low Pressure Losses

Recuperator Real (specific heat transfer)

Recuperator Max (specific heat transfer)

Thermal Power

Turbine

Turbine Outlet

Turbine Inlet

Recuperator inlet conditions

Compressor

Precooler

Core Outlet Temperature

Design Point 


$\begin{array}{ll}\text { GEN-IV } & \text { Generation Four } \\ \text { GFR } & \text { Gas-Cooled Fast Reactor } \\ \text { HP } & \text { High Pressure } \\ \text { HE } & \text { Recuperator } \\ \text { HPC } & \text { High Pressure Compressor } \\ \text { IC } & \text { Intercooled Cycle } \\ \text { ICR } & \text { Intercooled Cycle Recuperated } \\ \text { LMTD } & \text { Logarithmic Mean Temperature Difference } \\ \text { LP } & \text { Low Pressure } \\ \text { LPC } & \text { Low Pressure Compressor } \\ \text { M } & \text { Mixer (Figure 5) } \\ \text { NASA } & \text { National Aeronautics and Space Administration } \\ \text { NPP } & \text { Nuclear Power Plant } \\ \text { NTU } & \text { Number of Transfer Units } \\ \text { ODP } & \text { Off-Design Point } \\ \text { OPR } & \text { Overall Pressure Ratio } \\ \text { R } & \text { Reactor } \\ \text { RPV } & \text { Reactor Pressure Vessel } \\ \text { S } & \text { Splitter (Figure 5) } \\ \text { SC } & \text { Simple Cycle } \\ \text { SCR } & \text { Simple Cycle Recuperated } \\ \text { TET } & \text { Turbine Entry Temperature } \\ \text { VHTR } & \text { Very High Temperature Reactor } \\ & \end{array}$

\section{References}

1. Gad-Briggs, A.; Pilidis, P. Analyses of Simple and Intercooled Recuperated Direct Brayton Helium Gas Turbine Cycles for Generation IV Reactor Power Plants. J. Nucl. Eng. Radiat. Sci. 2016, 3, 011017. [CrossRef]

2. Locatelli, G.; Mancini, M.; Todeschini, N. Generation IV nuclear reactors: Current status and future prospects. Energy Policy 2013, 61, 1503-1520. [CrossRef]

3. Gad-Briggs, A.; Pilidis, P.; Nikolaidis, T. A Review of The Turbine Cooling Fraction for Very High Turbine Entry Temperature Helium Gas Turbine Cycles For Generation IV Reactor Power Plants. ASME J. Nucl. Eng. Radiat. Sci. 2016, 3, 021007. [CrossRef]

4. Pradeepkumar, K.N.; Tourlidakis, A.; Pilidis, P. Analysis of 115 MW, 3-Shaft, Helium Brayton Cycle using Nuclear Heat Source. Proc. ASME 2001. [CrossRef]

5. Pradeepkumar, K.N.; Tourlidakis, A.; Pilidis, P. Design and Performance review of PBMR Closed Cycle Gas Turbine Plant in South Africa. In Proceedings of the International Joint Power Generation Conference, New Orleans, LA, USA, 4-7 June 2001.

6. Pradeepkumar, K.N.; Tourlidakis, A.; Pilidis, P. Performance Review: PBMR Closed Cycle Gas Turbine Power Plant. In Proceedings of the Technical Committee Meeting on HTGR-Power Conversion Systems, Palo Alto, CA, USA, 14-16 November 2000; pp. 99-112.

7. Kulhanek, M.; Dostal, V. Supercritical carbon dioxide cycles. In Thermodynamic Analysis and Comparison; Czech Technical University Prague: Prague, Czech Republic, 2007.

8. Baxi, C.B.; Shenoy, A.; Kostin, V.I.; Kodochigov, N.G.; Vasyaev, A.V.; Belov, S.E.; Golovko, V.F. Evaluation of alternate power conversion unit designs for the GT-MHR. Nucl. Eng. Des. 2008, 238, 2995-3001. [CrossRef]

9. Gad-Briggs, A.; Pilidis, P.; Nikolaidis, T. Analyses of a High Pressure Ratio Intercooled Direct Brayton Helium Gas Turbine Cycle for Generation IV Reactor Power Plants. J. Nucl. Eng. Radiat. Sci. 2016, 3, 011021. [CrossRef]

10. Al-Busaidi, W.; Pilidis, P. An Approach to Evaluate The Heat Exchanger Retrofit for Installed Industrial Gas Turbines: Part I-Technical Evaluation. Int. J. Res. Eng. Technol. 2015, 4.

11. Al-Busaidi, W.; Pilidis, P. A Method To Evaluate The Heat Exchanger Retrofit For Industrial Gas Turbines Based on Technical and Economic Perspective. In Proceedings of the ASME Turbo Expo 2016: Turbomachinery Technical Conference and Exposition GT2016, Seoul, Korea, 13-17 June 2016. 
12. Sato, H.; Yan, X.L.; Tachibana, Y.; Kunitomi, K. GTHTR300-A nuclear power plant design with 50\% generating efficiency. Nucl. Eng. Des. 2014, 275, 190-196. [CrossRef]

13. Pitts, D.R.; Sissom, L.E. Theory and Problems of Heat Transfer, 2nd ed.; McGraw-Hill: New York, NY, USA, 1997.

14. Yeh, F.C.; Gladden, H.J.; Gauntner, J.W. Comparison of Heat Transer Characteristics of Three Cooling Configurations for Air Cooled Turbine Vanes Tested in a Turbojet Engine; NASA Lewis Research Center: Cleveland, $\mathrm{OH}$, USA, 1972.

15. Esgar, J.B.; Colladay, R.S.; Kaufman, A. An Analysis of the Capabilities and Limitations of Turbine Air Cooling Methods; NASA Lewis Research Center: Cleveland, OH, USA, 1970.

16. Meitner, P.L. Analysis of Metal Temperature and Coolant Flow with a Thermal Barrier Coating on Full-Coverage Film-Cooled Turbine Vane; NASA Lewis Research Center: Cleveland, OH, USA, 1978.

17. Han, J.C.; Dutta, S.; Ekkad, S. Gas Turbine Heat Transfer and Cooling Technology; Tayolr and Francis: New York, NY, USA, 2000.

18. Decher, R. Energy Conversion, Systems, Flow Physics and Engineering; Oxford Univesity Press: Oxford, UK, 1994.

(C) 2017 by the authors. Licensee MDPI, Basel, Switzerland. This article is an open access article distributed under the terms and conditions of the Creative Commons Attribution (CC BY) license (http:/ / creativecommons.org/licenses/by/4.0/). 